\title{
Pancreatic Ductal Adenocarcinoma: New Insights into the Actions of Vitamin A
}

\author{
Eduardo Mere Del Aguila Xiao-Han Tang Lorraine J. Gudas \\ Department of Pharmacology, Weill Cornell Medicine, New York, NY, USA
}

\section{Keywords}

Pancreas · Pancreatic cancer - Pancreatic stellate cells · Retinoic acid receptors

\begin{abstract}
Background: Pancreatic ductal adenocarcinoma (PDAC) is a gland-forming malignancy arising in the pancreas. It is estimated that in developed countries the incidence of PDAC will continue to rise, and PDAC is now the fourth leading cause of cancer-related deaths in the USA. The mortality of PDAC patients closely parallels the incidence rate, as this malignancy generally remains asymptomatic until it reaches an advanced stage. Summary: The poor prognosis results from the aggressive nature of the tumor, late detection, and resistance to chemotherapy and radiotherapy. Retinoids, vitamin $A$ (retinol) and its metabolites, such as retinoic acid (RA), play critical roles in important biological functions, including cell growth and differentiation, development, metabolism, and immunity. The actions of retinoids in maintaining normal pancreatic functions have generated considerable research interest from investigators interested in understanding and treating PDAC. Altered expression of retinoid receptors and other RA signaling pathway genes in human cancers offers opportunities for target discovery, drug design, and personalized medicine for distinct molecular retinoid subtypes. Key Messages: The goals of this review are to explore the potential activities of retinoids in the pancreas, to assess the evidence that retinoid functions become dysregulated in PDAC, and to describe the actions of retinoids in new therapies developed to increase patient survival.
\end{abstract}

(c) 2022 The Author(s).

Published by S. Karger AG, Basel

Karger@karger.com www.karger.com/ort

Karger ${ }^{\prime \prime}=$

bOPEN ACCESS
(C) 2022 The Author(s)

Published by S. Karger AG, Basel

This is an Open Access article licensed under the Creative Common Attribution-NonCommercial-4.0 International License (CC BY-NC) (http://www.karger.com/Services/OpenAccessLicense), applicable to the online version of the article only. Usage and distribution for commercial purposes requires written permission.

\section{Introduction}

Pancreatic ductal adenocarcinoma (PDAC) is a highly lethal malignancy. It is the fourth leading cause of cancerrelated death in the USA [1]. Unfortunately, due to its late presentation, only $15-20 \%$ of patients are candidates for surgical intervention. PDAC is predicted to become the second leading cause of cancer death within a decade if progress in treatment continues to be only incremental [2]. PDAC is characterized by rapid progression, an extremely poor prognosis, and limited treatment options [3].

Among the factors that increase the risk of this malignancy are obesity, cigarette smoking, and increased consumption of animal fat [4]. A greater risk for PDAC development is also associated with pancreatitis, type 2 diabetes [5, 6], and Helicobacter pylori infection [7]. Disruptions/mutations in various genes (TP53, SMAD4, ARID1A, ROBO2, KDM6A, PREX2) increase the incidence of PDAC [8].

K-RAS mutations occur very frequently in pancreatic cancer [9]. K-RAS activity is an important and early event in tumorigenesis $[10,11]$. Various studies show that an activating mutation in K-RAS occurs in from 47 to $100 \%$ of PDAC cases, most commonly at codon 12 [12-14].

FOLFIRINOX (the combination of folinic acid, 5-fluorouracil (5-FU), irinotecan, and oxaliplatin), a cancer therapy, is reported to have a survival advantage compared to gemcitabine (a DNA synthesis inhibitor) alone for PDAC treatment [15]. Nab-paclitaxel (an antimicrotubular agent), a combination therapy with albuminbased nab-paclitaxel and gemcitabine, is associated with

Correspondence to:

Lorraine J. Gudas, ljgudas@med.cornell.edu 
significant improvement in median overall survival (OS) and progression-free survival compared to gemcitabine alone [16].

Retinoids are defined as a group of micronutrients that include vitamin A (retinol) and its metabolites. All-trans retinoic acid (RA) is the biologically active form of vitamin A because RA acts as an agonist for the RA receptors (RAR- $\alpha$, RAR- $\beta$, and RAR- $\gamma$ ) to regulate gene expression [17]. Various retinoids are used as chemotherapeutic agents in oncology [18]. Retinoids are effective components of some current cancer therapies because they can act both by promoting stem cell differentiation and changing the pattern of gene expression in tumor cells to make them more sensitive to other therapies [19]. Recently, a clinical trial of RA in pancreatic cancer has started [20]. Because of this clinical interest in retinoids for PDAC treatment and epidemiological studies demonstrating an inverse relationship between dietary vitamin A consumption and PDAC development [21], here we explore the actions of retinoids in the normal pancreas and in PDAC.

\section{General Overview of the Actions of Retinoids}

Retinoids are naturally occurring, low-molecularweight, fat-soluble, unsaturated isoprenoids that play essential roles in various aspects of mammalian physiology, including spermatogenesis, fertilization, pregnancy maintenance, morphogenesis, organogenesis, and fetal and perinatal growth. Retinaldehyde plays a key role in vision, and RA in gene regulation. Nutritional deficiency in vitamin $\mathrm{A}$ is still a major public health concern in the developing world, causing blindness and death [22].

RA inhibits cell proliferation and induces cell differentiation in many malignant tissues [18]. RA exerts its pleiotropic effects on cellular growth and differentiation through acting as a ligand for the RA receptors (RARs). The transcriptional regulatory activity of RA is mediated by 6 distinct ligand-dependent transcription factors, 3 RARs (RAR- $\alpha$, RAR- $\beta$, and RAR- $\gamma$ ), and 3 retinoid X receptors (RXR- $\alpha$, RXR- $\beta$, and RXR- $\gamma$ ). The RARs and RXRs are members of the steroid/thyroid/retinoid superfamily of nuclear hormone receptors and recognize specific response elements present within genes to then regulate transcription and subsequent epigenetic changes [23]. Most retinoid actions within the body involve transcriptional regulatory effects that are mediated primarily by RA [17]. Thus, RA is a potent transcriptional regulator that directly controls expression of more than 500 genes, and these RA target genes vary in different cell types [24]. The three different RARs regulate unique and different target genes [24].

RA has a well-studied, essential role in patterning in the development of numerous organs, including the hindbrain, spinal cord, heart, eyes, forelimbs, buds, lungs, genitourinary tract, and pancreas [25]. Deficient or excessive retinoid signaling, arising either through dietary retinoid-insufficiency or through alterations in genes involved in retinoid metabolism or signaling, can give rise to a wide spectrum of embryonic defects, emphasizing the importance of the regulation of intracellular metabolites of all-trans retinol $(\mathrm{ROH})$ and the proper levels of RA for assuring normal embryonic development [26]. The synthesis and degradation of RA are complex processes, however, involving many specific proteins and enzymes (Fig. 1). Retinoids (retinyl esters, retinol, and provitamin A carotenoids, such as $\beta$-carotene) must be obtained from the diet [27].

\section{Retinoids in the Pancreas: Glucose Regulation}

Retinol ( $\mathrm{ROH})$ is required for the maintenance of both pancreatic $\beta$-cell mass and for glucose-stimulated insulin secretion in adult mice $[28,29]$. Reintroduction of retinoids into the diet of retinoid-deficient mice restored pancreatic retinoid levels, glycemic control, normal islet size distribution, normal $\beta$-cell to $\alpha$-cell ratios, endocrine hormone profiles, and RAR $\beta 2$ and RAR $\gamma 2$ transcript levels [29]. It is also clear that retinoids are needed to maintain $\beta$-cell mass within islets and to prevent $\beta$-cell apoptosis [29].

In adult rodents, an isomer of all-trans RA, 9-cis-RA, rapidly attenuates glucose sensing and insulin secretion, and pancreatic 9-cis-RA levels vary inversely with serum insulin levels [30]. Importantly, both RA and $\mathrm{ROH}$ levels are reduced in human PDAC tissue compared to healthy tissue, and the levels of these retinoids are similarly reduced in pancreata obtained from a mouse PDAC model [31]. Patients are often hyperglycemic for a mean period of 36-30 months before PDAC diagnosis [32], which is associated with the fact that both RA and $\mathrm{ROH}$ levels are reduced in human PDAC tissue.

\section{Retinoid Actions in Pancreatic Development}

The pancreas is composed of endocrine and exocrine compartments which are responsible for maintaining body glucose homeostasis and digesting food, respectively [33]. The endocrine pancreas is defined by islet cells which secrete hormones, such as insulin and glucagon, to regulate the blood glucose level. The RA-signaling pathway plays critical roles in a wide range of developmental processes at multiple stages during embryogenesis [34]. In the pancreas, RA signaling is necessary for the onset of pancreagenesis; previous studies have demonstrated that inhibition of this RA signaling pathway leads to pancreas agenesis [35]. 


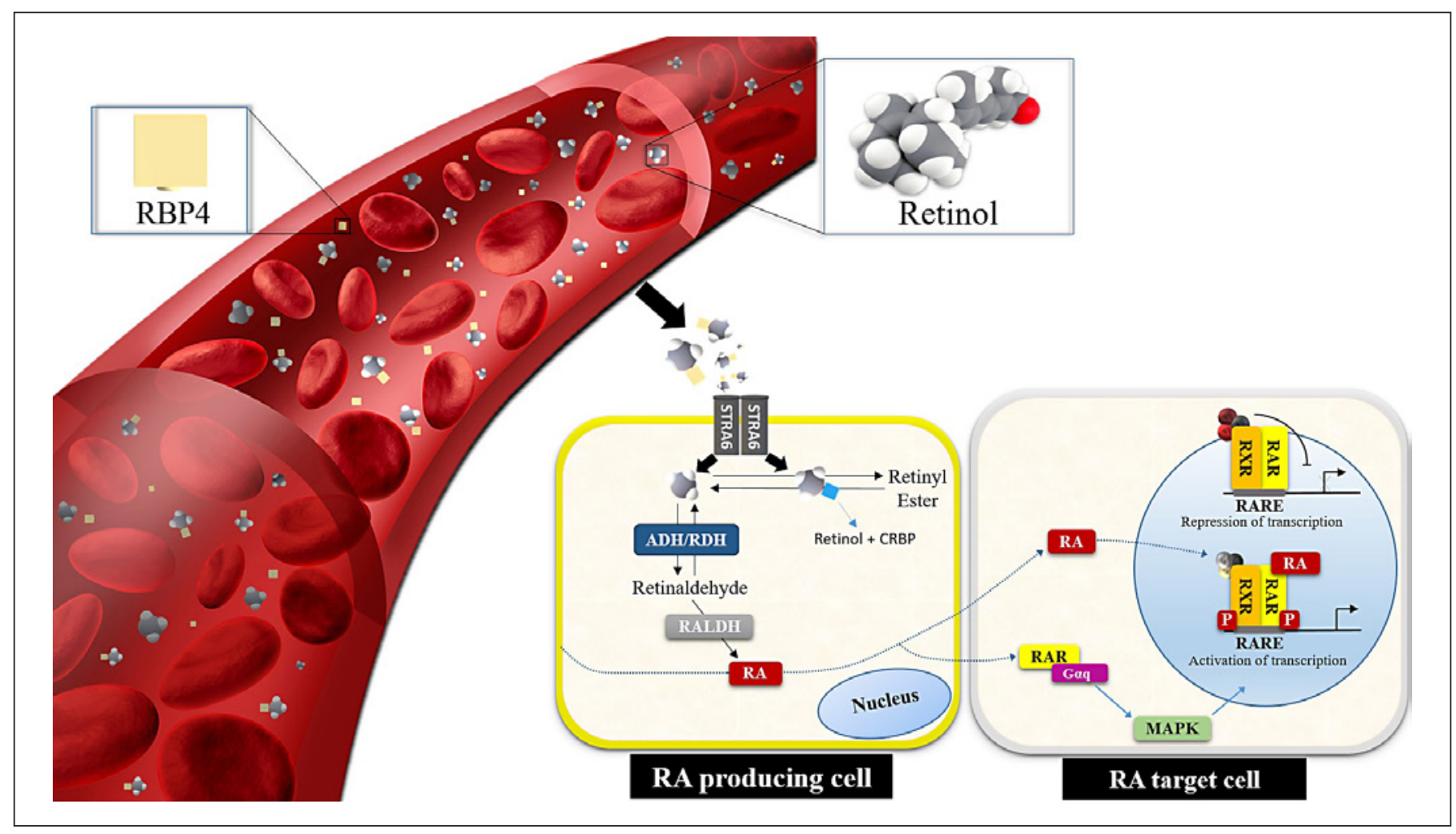

Fig. 1. Simplified scheme for the retinoid signaling pathway. Blood-circulating retinol is internalized through membrane transporter and receptor STRA6, not in all cell types, however it is converted into all-trans $R A$, which binds to CRABP2 for signaling in the nucleus. RA triggers gene transcription by binding to RARs and to retinoid X receptors (RXRs). In the presence of the ligand, RAR and RXR heterodimerize on RARE sequences located in pro-

High levels of RA are crucial for initial pancreas specification, and RA is used in several protocols for stem cell differentiation and for pancreatic endoderm specification in culture. This use of RA is also supported by gene expression analyses in mice demonstrating the presence of many key RA pathway genes in the embryonic pancreas [36]. Exocrine cell differentiation is also controlled in part by retinoid signaling during development [37].

The disruption of RA signaling in all pancreatic progenitors led to the formation of a smaller pancreas that contained fewer $\beta$ (Insulin), a (Glucagon), and $\delta$ (Somatostatin) cells at embryonic day e16.5 and e18.5 [38]. Disrupting RA signaling using the tamoxifen-inducible Pdx1:creEsr1 allele at e9.5, a slightly later stage of development after the pancreatic progenitor population has been established, also resulted in the formation of a smaller pancreas and a significant reduction in islet cluster formation and fewer hormone producing cells [39]. Recent results further establish the importance of RA signaling in the endocrine progenitor population for appropriate mouse and human $\beta$-cell specification [40]. moter regions inducing the transcription of target genes. $\mathrm{ADH}$, alcohol dehydrogenase; CRBP, cellular retinol-binding protein 1; Gaq, Gq protein alpha subunit; MAPK, mitogen-activated protein kinases; RALDH, retinaldehyde dehydrogenase; RBP4, retinolbinding protein 4; RDH, retinol dehydrogenase; STRA6, stimulated by RA 6; RARE, RA-response element.

\section{Retinoid Actions in Pancreatic Acinar Cells}

The exocrine pancreas consists of acinar cells which synthesize digestive enzymes such as amylase, and ductal cells responsible for transport of digestive enzymes to the duodenum for digestion. Acinar cells are enzyme-secreting cells that release amylase, lipases, and proteases; some differentiated acinar cell identity proteins include Ptf1a, MIST1, GATA6, NR5A2, and PAF1 [41]. Debate exists regarding whether acinar cell carcinoma of the pancreas is unique from PDAC $[42,43]$. However, acinar cell carcinoma of the pancreas responds to treatment differently and rates of OS (overall survival) are not similar [44].

PDACs form pancreatic duct-like structures under the microscope and are therefore called "pancreatic ductal adenocarcinomas (PDACs)," which are among the deadliest malignancies in humans [1]. There is some evidence that PDAC may originate from pancreatic ductal cells through the development of pancreatic intraepithelial neoplasias after the first activating gene mutation in KRAS [45]. In addition to pancreatic ductal cells, pancreatic acinar cells (PAC) contribute to the development of 
PDAC through acinar-to-ductal metaplasia (ADM) [46]. In ADM, PAC can dedifferentiate to an embryonic progenitor phenotype that expresses ductal markers [41]. The concept that acinar cell plasticity plays an important role in PDAC tumorigenesis has received increasing attention more recently $[47,48]$. When acinar cells receive inflammatory signals during pancreatic injury, such as pancreatitis, ADM can occur. Research with mouse models suggests that in PDAC the cell of origin is the mature acinar cell, and pancreatitis-induced ADM has been proposed as a potential mechanism of PDAC initiation in mice [47]. Indeed, pancreatitis is the top risk factor for PDAC in humans $[49,50]$. However, how pancreatitis accelerates PDAC development is not well understood.

Multiple factors have been implicated in mediating $\mathrm{ADM}$, such as K-RAS hyperactivity and increased inflammatory signaling [51-53]; in the presence of internal or external stress signaling of oncogenic K-RAS, inflammatory cytokines, or growth factors that activate epidermal growth factor receptor, acinar cells can spontaneously transdifferentiate into duct-like structures $[47,54]$. For instance, Sox 9 is not normally expressed in acinar cells [55], but in the presence of hyperactive K-RAS, higher expression of Sox9 in ductal and centroacinar cells is induced during ADM, and Sox9 is expressed at high levels in pancreatic intraepithelial neoplasias [56-58].

$\mathrm{RA}$ is an important signaling molecule in the development of the embryonic pancreas and plays a major role in the differentiation of endocrine and ductal cells, predominantly through paracrine actions and upregulation of PDX-1 during development [59]. In the K-ras ${ }^{\mathrm{LSL}} \mathrm{G} 12 \mathrm{D} /+$; $\mathrm{Pdx}-1$-Cre (KC) transgenic murine model of PDAC researchers demonstrated that inhibition of 15-hydroxyprostaglandin dehydrogenase increased Cyp26al levels (Fig. 1), resulting in a reduction in RA in the pancreas and an enhancement of K-RAS-driven PDAC progression. Furthermore, pharmacological doses of RA suppressed 15-hydroxyprostaglandin dehydrogenase inhibition-induced tumor progression in these KC mice [60].

In the normal pancreas, significant RA signaling in the adult is reported to be restricted to the islets and a small number of exocrine (acinar and centro-acinar) cells, as shown by an RA responsive element being activated in a murine model (RARE-LacZ) [61]. However, when these same RARE-LacZ mice are treated with cerulein, which can induce cell damage and subsequent pancreatitis, loss of acinar cell mass, pancreatic fibrosis, and ADM, they show increased retinoid signaling, as assessed by LacZ, in a large percentage of acinar cells immediately after the cerulein treatment is stopped [61]. These data suggest that RA signaling is activated to repair and regenerate the acinar cell population following injury. This could involve dedifferentiation of acinar cells to a more stem-like state or differentiation of stem cells in the pancreas [62].

\section{Retinoid Actions in Pancreatic Stellate Cells}

Pancreatic stellate cells (PSCs) are fibroblastic cells that represent $4-7 \%$ of all pancreatic cells. PSCs also play an essential role in the regeneration of the pancreas after partial pancreatectomy. In the liver, about $50 \%-80 \%$ of vitamin $\mathrm{A}$ in the body is stored in hepatic stellate cells as retinyl esters $[63,64]$. Normal PSCs are quiescent and store retinol in cytoplasmic, lipid vesicles; however, during PDAC progression they lose vitamin $\mathrm{A}$ and acquire an activated, myofibroblast-like, contractile phenotype [65]. Proliferation of acinar and islet cells increases when co-cultured with activated PSCs, suggesting that PSC activation could promote PDAC progression [66]. Retinoids are involved in preventing or slowing PSC activation and disease progression [67]. In humans, PSCs express all three RA receptors (RARs), albeit at different levels, and treatment with RA mechanically reprograms PSCs to promote quiescence in vitro and inhibit pancreatic cancer cell invasion $[31,68]$.

In chronic disease, the repeated activation of PSCs causes pancreatic fibrosis, characterized by disruption of the normal cytoarchitecture and excessive deposition of extracellular matrix, particularly fibrillar collagens, proteoglycans, and fibronectin [64]. In the tumor environment, TGF- $\beta$ can be released from cancer cells, infiltrating immune cells, or atypical acinar cells [64]. Importantly, PSC activation by TGF- $\beta$ can initiate an autocrine, positive feedback loop which perpetuates an activated PSC phenotype [65]. PDAC is characterized by a strong desmoplastic reaction or stromal fibrosis which is driven by PSCs and may create a microenvironment that regulates tumor growth, metastasis, and chemoresistance [69]. This desmoplastic reaction has been the focus of several studies that have concentrated on the complex nature of the stromal components and their contributions to disease progression [70-72]. All of these observations about the behavior of PSCs are important because activated PSCs promote growth of PDAC [73], and the excessive extracellular matrix (called desmoplasia, desmoplastic reaction, or stromal reaction to a tumor) also increases the resistance of pancreatic cancers to chemotherapy and radiation. PSCs additionally indirectly stimulate tumor growth and metastasis by promoting angiogenesis $[65$, 74].

RA has the ability to reduce the activation of stellate cells in both liver and pancreas [75]. Human PDAC samples show greatly reduced RA signaling and levels of retinoid receptors [31]. For this reason, targeting PSC activation can be considered as a useful therapeutic strategy in PDAC, and understanding the roles played by retinoids in the modulation of the quiescent/activated state of PSCs is certainly of importance $[31,76]$. PSCs reduce their proliferation and synthesis of extracellular matrix and 
a-smooth muscle actin when they are treated with RA or vitamin A $[77,78]$. RA promotes the quiescent, nonactivated state of PSCs [67], and elimination of activated PSCs can also occur via apoptosis [79]. RA also restores mechanical quiescence in PSCs through a mechanism involving RA receptor beta (RAR $\beta$ )-dependent reduction in actomyosin contractility [80]. RA treatment reduces the ability of PSCs to generate high traction forces and to adapt to extracellular mechanical cues; suppression of force-mediated extracellular matrix remodeling inhibits local cancer cell invasion in three-dimensional organotypic models [80].

Patients with PDAC demonstrated significantly lower levels of vitamin A, as measured previously in other studies $[81,82]$. An inverse correlation between serum pentraxin 3, a protein associated with local inflammation, and VA levels was found in this study, andRA treatment reducesthe PTX3 protein level [81].

\section{Effects of RA with Other Therapies for Pancreatic Cancer}

RA possesses antitumor activity in part through its ability to induce cellular differentiation. Even though retinoids show promising preclinical activity in human solid tumors, they have not yet been translated into effective systemic treatments for PDAC. We think that recognizing how retinoids function in pancreatic tumor cells could provide insights into how to design more successful approaches and strategies for retinoid therapies.

One major effect of RA is an increase in RAR levels in different cells, especially an increase in RAR $\beta$ [83]. Decreased expression of RAR $\beta$ has been suggested to play a key role in the maintenance of the malignant phenotype in human PDAC [84]. In animal studies, stimulation of RAR $\alpha$ by retinoids resulted in a time- and dose-dependent inhibition of PDAC cell growth [85]. RA also inhibited pancreatic carcinoma cell migration and epithelialmesenchymal transition of tumor cells through downregulation of IL-6 in cancer-associated fibroblasts [86], and RA reduced the stem-like attributes of PDAC cells [87]. Collectively, these data provide biological evidence that RA could potentially be used for the prevention of recurrence and/or metastasis in pancreatic cancer [88].

Numerous studies in cell culture and in animal models have demonstrated additive or synergistic actions of RA in combination with other chemotherapeutic agents. The combination of 13-cis-RA and interleukin 2 has been used for treating locally advanced pancreatic cancer [89]. In the K-ras ${ }^{\text {LSL.G12D/+}}$; Trp53 $3^{\mathrm{R} 172 \mathrm{H} /+} ; \mathrm{Pdx}-1-\mathrm{Cre}$ (KPC) transgenic mouse model, RA plus gemcitabine reduced tumor growth by acting on multiple signaling pathways [78].
RA shows some inhibitory effects on pancreatic cancer cells and enhances the therapeutic index of chemotherapeutic drugs such as gemcitabine, cisplatin, doxorubicin, etoposide, and paclitaxel [90-94]. Moreover, RA can target PSCs, which are part of the desmoplastic stroma surrounding cancer cells, acting as a barrier for chemotherapeutic drugs and thus generally promoting tumor growth and resistance $[95,96]$.

In PDAC cell lines, RA plus gemcitabine synergistically reduced proliferation in part by decreasing expression of p21 activated kinases [93], and by inhibiting KRAS activation [97]. Interestingly, in a phase I trial conducted in patients with diverse solid tumors the HDAC inhibitor MS- 275 (Entinostat), in combination with 13-cis-RA, prolonged stable disease (6 months) in a patient with unresectable, chemotherapy-resistant pancreatic cancer, thus suggesting some effectiveness of this combination in controlling disease progression [98]. Repurposing RA as a stromal-targeting agent with gemcitabine-nab-paclitaxel is likely safe and tolerable. This combination will be evaluated in a phase II randomized controlled trial for locally advanced PDAC [20].

The clinical application of RA is, however, hampered by its hydrophobicity, poor bioavailability, and instability; thus, some researchers have used a nanoparticulate system for drug delivery purposes [99]. 13-cis RA and 1, $25-V D 3$ could function as chemopreventive agents to alleviate TNF- $\alpha$-mediated expression of MMP-9 through blockade of JNK and NF-kB signaling pathways in human PDAC cells. Co-treatment of 13-cis-RA and 1,25-Vitamin D3 blocked cell invasion and induced the expression of TIMP-3 through an inactivation of JNK pathways and downregulation of miR-221 [100].

The Know Your Tumour trial is the first specifically in PDAC to demonstrate longer survival in patients who received matched therapies relative to those with actionable mutations who received unmatched therapies and those who bore no such alterations, with a median OS of 1 year or longer [101]. Various studies have also been conducted to evaluate the chemopreventive potential of retinoids as single agents and in combination drug regimens with other chemotherapeutic agents $[102,103]$.

\section{Conclusions}

Important questions regarding the potential roles of retinoids in preventing pancreatic cancer development need to be answered. For instance, it is necessary to establish which genes that play critical roles in pancreas development are induced or regulated by retinoids and also act in PDAC prevention/treatment. Personalized cancer care is anchored on the premise that a patient's cancer can be molecularly characterized in real time, informing prog- 
nosis and predicting therapeutic responses. For that reason, it will be necessary to obtain a more precise understanding of the activation of genes involved in retinoid metabolism and of how the levels of retinoids may influence the survival of patients with PDAC. Future therapeutic approaches will benefit from RNA sequencing of tumors to determine the status of RA signaling genes when administering RA-based treatments to oncology patients [102].

Future research could also provide important information by identifying which retinoids are active against tumor cells that carry specific mutations. Furthermore, continued research on RA signaling mechanisms and the dysregulation of RA signaling in cancer should provide valuable insights into how new retinoid-targeted therapies might be designed for PDAC patients.

\section{Conflict of Interest Statement}

The authors have no conflicts of interest to declare.

\section{Funding Sources}

NIH ROI CA205258 to L.J.G., Cancer Pharmacology Training Grant T32 CA062948 to E.M.D.A., and Weill Cornell Funds.

\section{Author Contributions}

E.M.D.A. wrote the paper, and X.-H.T. and L.-J.G. edited and revised the paper. All authors read and approved the final manuscript.

\section{References}

1 Siegel RL, Miller KD, Jemal A, Jemal A. Cancer statistics, 2017. CA Cancer J Clin. 2021 Jan;67(1):7-30.

2 Ryan DP, Hong TS, Bardeesy N. Pancreatic adenocarcinoma. N Engl J Med. 2014 Sep; 371(11):2140-1.

3 Gillen S, Schuster T, Meyer Zum Büschenfelde C, Friess H, Kleeff J. Preoperative/neoadjuvant therapy in pancreatic cancer: a systematic review and meta-analysis of response and resection percentages. PLoS Med. 2010 Apr; 7(4):e1000267.

4 McGuigan A, Kelly P, Turkington RC, Jones C, Coleman HG, McCain RS. Pancreatic cancer: A review of clinical diagnosis, epidemiology, treatment and outcomes. World J Gastroenterol. 2018 Nov;24(43):4846-61.

5 Ben Q, Xu M, Ning X, Liu J, Hong S, Huang $\mathrm{W}$, et al. Diabetes mellitus and risk of pancreatic cancer: a Meta-Analysis of Cohort Studies. Eur J Cancer. 2011 Sep;47(13):1928-37.

6 Li D, Tang H, Hassan MM, Holly EA, Bracci PM, Silverman DT. Diabetes and risk of pancreatic cancer: a pooled analysis of three large case-control studies. Cancer Causes Control. 2011 Feb;22(2):189-97.

7 Trikudanathan G, Philip A, Dasanu CA, Baker WL. Association between helicobacter pylori infection and pancreatic cancer. A cumulative meta-analysis. JOP. 2011 Jan;12(1):2631.

8 Cancer Genome Atlas Research Network. Integrated genomic characterization of pancreatic ductal adenocarcinoma. Cancer Cell. 2017 Aug 14;32(2):185-203.e13.

9 Fuccio L, Hassan C, Laterza L, Correale L, Pagano $\mathrm{N}$, Bocus $\mathrm{P}$, et al. The role of $\mathrm{K}$-ras gene mutation analysis in EUS-guided FNA cytology specimens for the differential diagnosis of pancreatic solid masses: a meta-analysis of prospective studies. Gastrointest Endosc. 2013 Oct;78(4):596-608.

10 Malumbres M, Barbacid M. RAS oncogenes: the first 30 years. Nat Rev Cancer. 2003 Jun 3(6):459-65.
11 Duffy MJ, Sturgeon C, Lamerz R, Haglund C, Holubec VL, Klapdor R, et al. Tumor markers in pancreatic cancer: a European Group on Tumor Markers (EGTM) status report. Ann Oncol. 2010 Mar;21(3):441-7.

12 Zhang C, Guo W, Wu J, Song B, Dai Q, Pan $B$, et al. Differential high-resolution melting analysis for the detection of K-ras codons 12 and 13 mutations in pancreatic cancer. Pancreas. 2011 Nov;40(8):1283-8.

$13 \mathrm{Gu}$ J, Wang D, Huang Y, Lu Y, Peng C. Diagnostic value of combining CA 19-9 and K-ras gene mutation in pancreatic carcinoma: a meta-analysis. Int J Clin Exp Med. 2014;7(10): 3225-34.

14 Kinugasa H, Nouso K, Miyahara K, Morimoto Y, Dohi C, Tsutsumi K, et al. Detection of $\mathrm{K}$-ras gene mutation by liquid biopsy in patients with pancreatic cancer. Cancer. 2015 Jul;121(13):2271-80.

15 Conroy T, Desseigne F, Ychou M, Bouché O, Guimbaud R, Bécouarn Y, et al. FOLFIRINOX versus gemcitabine for metastatic pancreatic cancer. N Engl J Med. 2011 May; 364(19):1817-25.

16 Von Hoff DD, Ervin T, Arena FP, Chiorean EG, Infante J, Moore M, et al. Increased survival in pancreatic cancer with nab-paclitaxel plus gemcitabine. N Engl J Med. 2013 Oct; 369(18):1691-703.

17 Chawla A, Repa JJ, Evans RM, Mangelsdorf DJ. Nuclear receptors and lipid physiology: opening the $X$-files. Science. 2001 Nov; 294(5548):1866-70.

18 Tang XH, Gudas LJ. Retinoids, retinoic acid receptors, and cancer. Annu Rev Pathol. 2011; 6:345-64.

19 Gudas LJ, Wagner JA. Retinoids regulate stem cell differentiation. J Cell Physiol. 2011 Feb; 226(2):322-30.

20 Kocher HM, Basu B, Froeling FEM, Sarker D, Slater S, Carlin D, et al. Phase I clinical trial repurposing all-trans retinoic acid as a stromal targeting agent for pancreatic cancer. Nat Commun. 2020 09;11(1):4841.
21 Doldo E, Costanza G, Agostinelli S, Tarquini C, Ferlosio A, Arcuri G, et al. Vitamin A, cancer treatment and prevention: the new role of cellular retinol binding proteins. Biomed Res Int. 2015;2015:624627.

22 Sommer A, Vyas KS. A global clinical view on vitamin A and carotenoids. Am J Clin Nutr. 2012 Nov;96(5):1204S-6S.

23 di Masi A, Leboffe L, De Marinis E, Pagano F, Cicconi L, Rochette-Egly C, et al. Retinoic acid receptors: from molecular mechanisms to cancer therapy. Mol Aspects Med. 2015 Feb;41:1-115.

24 Balmer JE, Blomhoff R. Gene expression regulation by retinoic acid. J Lipid Res. 2002 Nov; 43(11):1773-808

25 Duester G. Retinoic acid synthesis and signaling during early organogenesis. Cell. 2008 Sep;134(6):921-31.

26 Rhinn M, Dollé P. Retinoic acid signalling during development. Development. 2012 Mar;139(5):843-58.

27 O'Byrne SM, Blaner WS. Retinol and retinyl esters: biochemistry and physiology. J Lipid Res. 2013 Jul;54(7):1731-43.

28 Brun PJ, Grijalva A, Rausch R, Watson E, Yuen JJ, Das BC, et al. Retinoic acid receptor signaling is required to maintain glucosestimulated insulin secretion and beta-cell mass. FASEB J. 2015 Feb;29(2):671-83.

29 Trasino SE, Benoit YD, Gudas LJ. Vitamin A deficiency causes hyperglycemia and loss of pancreatic $\beta$-cell mass. J Biol Chem. 2015 Jan 16;290(3):1456-73.

30 Kane MA, Folias AE, Pingitore A, Perri M, Obrochta KM, Krois CR, et al. Identification of 9-cis-retinoic acid as a pancreas-specific autacoid that attenuates glucose-stimulated insulin secretion. Proc Natl Acad Sci U S A. 2010 Dec;107(50):21884-9.

31 Bleul T, Rühl R, Bulashevska S, Karakhanova S, Werner J, Bazhin AV. Reduced retinoids and retinoid receptors' expression in pancreatic cancer: A link to patient survival. Mol Carcinog. 2015 Sep;54(9):870-9. 
32 Sharma A, Smyrk TC, Levy MJ, Topazian MA, Chari ST. Fasting blood glucose levels provide estimate of duration and progression of pancreatic cancer before diagnosis. Gastroenterology. 2018 08;155(2):490-e2.

33 Wong CH, Li YJ, Chen YC. Therapeutic potential of targeting acinar cell reprogramming in pancreatic cancer. World J Gastroenterol. 2016 Aug;22(31):7046-57.

34 Ghyselinck NB, Duester G. Retinoic acid signaling pathways. Development. 2019 07; 146(13).

35 Zhou Y, Wang H, Zhou J, Qiu S, Cai T, Li H, et al. Vitamin A and Its multi-effects on pancreas: recent advances and prospects. Front Endocrinol. 2021;12:620941.

36 Krentz NAJ, Lee MYY, Xu EE, Sproul SLJ, Maslova A, Sasaki S, et al. Single-cell transcriptome profiling of mouse and hESC-derived pancreatic progenitors. Stem Cell Reports. $2018 \mathrm{Dec} ; 11(6)$ :1551-64.

37 Kobayashi H, Spilde TL, Bhatia AM, Buckingham RB, Hembree MJ, Prasadan K, et al. Retinoid signaling controls mouse pancreatic exocrine lineage selection through epithelialmesenchymal interactions. Gastroenterology. 2002 Oct;123(4):1331-40.

38 Ostrom M, Loffler KA, Edfalk S, Selander L, Dahl U, Ricordi C, et al. Retinoic acid promotes the generation of pancreatic endocrine progenitor cells and their further differentiation into beta-cells. PLoS One. 2008 Jul 30 3(7):e2841.

39 Gu G, Dubauskaite J, Melton DA. Direct evidence for the pancreatic lineage: NGN3+ cells are islet progenitors and are distinct from duct progenitors. Development. 2002 May 129(10):2447-57.

40 Lorberbaum DS, Kishore S, Rosselot C, Sarbaugh D, Brooks EP, Aragon E, et al. Retinoic acid signaling within pancreatic endocrine progenitors regulates mouse and human $\beta$ cell specification. Development. 2020 Jun; 147(12).

41 Storz P. Acinar cell plasticity and development of pancreatic ductal adenocarcinoma Nat Rev Gastroenterol Hepatol. 2017 May; 14(5):296-304

42 Matos JM, Schmidt CM, Turrini O, Agaram NP, Niedergethmann M, Saeger HD, et al. Pancreatic acinar cell carcinoma: a Multi-Institutional Study. J Gastrointest Surg. 2009 Aug;13(8):1495-502.

43 Kong B, Michalski CW, Erkan M, Friess H, Kleeff J. From tissue turnover to the cell of origin for pancreatic cancer. Nat Rev Gastroenterol Hepatol. 2011 07;8(8):467-72.

44 Wang Y, Wang S, Zhou X, Zhou H, Cui Y, Li $\mathrm{Q}$, et al. Acinar cell carcinoma: a report of 19 cases with a brief review of the literature. World J Surg Oncol. 2016 Jun;14(1):172.

45 Ray KC, Bell KM, Yan J, Gu G, Chung CH, Washington MK, et al. Epithelial tissues have varying degrees of susceptibility to $\operatorname{Kras}(\mathrm{G} 12 \mathrm{D})$-initiated tumorigenesis in a mouse model. PLoS One. 2011 Feb;6(2): e16786.

46 Zhu L, Shi G, Schmidt CM, Hruban RH, Konieczny SF. Acinar cells contribute to the molecular heterogeneity of pancreatic intraepithelial neoplasia. Am J Pathol. 2007 Jul; 171(1):263-73.
47 Shi G, DiRenzo D, Qu C, Barney D, Miley D, Konieczny SF. Maintenance of acinar cell organization is critical to preventing Kras-induced acinar-ductal metaplasia. Oncogene. 2013 Apr;32(15):1950-8.

48 Kopp JL, Grompe M, Sander M. Stem cells versus plasticity in liver and pancreas regeneration. Nat Cell Biol. 2016 Mar;18(3):23845.

49 Gukovsky I, Li N, Todoric J, Gukovskaya A, Karin M. Inflammation, autophagy, and obesity: common features in the pathogenesis of pancreatitis and pancreatic cancer. Gastroenterology. 2013 Jun;144(6):1199-e4.

50 Becker AE, Hernandez YG, Frucht H, Lucas AL. Pancreatic ductal adenocarcinoma: risk factors, screening, and early detection. World J Gastroenterol. 2014 Aug;20(32):11182-98.

51 Hezel AF, Gurumurthy S, Granot Z, Swisa A, Chu GC, Bailey G, et al. Pancreatic LKB1 deletion leads to acinar polarity defects and cystic neoplasms. Mol Cell Biol. 2008 Apr;28(7): 2414-25.

52 Liou GY, Döppler H, Necela B, Krishna M, Crawford HC, Raimondo M, et al. Macrophage-secreted cytokines drive pancreatic acinar-to-ductal metaplasia through NF- $\kappa \mathrm{B}$ and MMPs. J Cell Biol. 2013 Aug;202(3):563-77.

53 Liou GY, Döppler H, DelGiorno KE, Zhang L, Leitges M, Crawford HC, et al. Mutant KRasinduced mitochondrial oxidative stress in acinar cells upregulates EGFR signaling to drive formation of pancreatic precancerous lesions. Cell Rep. 2016 Mar;14(10):2325-36.

54 Liou GY, Döppler H, Braun UB, Panayiotou R, Scotti Buzhardt M, Radisky DC, et al. Protein kinase D1 drives pancreatic acinar cell reprogramming and progression to intraepithelial neoplasia. Nat Commun. 2015 Feb;6:6200.

55 Seymour PA, Freude KK, Tran MN, Mayes EE, Jensen J, Kist R, et al. SOX9 is required for maintenance of the pancreatic progenitor cell pool. Proc Natl Acad Sci U S A. 2007 Feb; 104(6):1865-70

56 Morris JP, Cano DA, Sekine S, Wang SC, Hebrok M. Beta-catenin blocks Kras-dependent reprogramming of acini into pancreatic cancer precursor lesions in mice. J Clin Invest. 2010 Feb;120(2):508-20.

57 Kopp JL, von Figura G, Mayes E, Liu FF, Dubois CL, Morris JP, et al. Identification of Sox9-dependent acinar-to-ductal reprogramming as the principal mechanism for initiation of pancreatic ductal adenocarcinoma. Cancer Cell. 2012 Dec;22(6):737-50.

58 Prévot PP, Simion A, Grimont A, Colletti M, Khalaileh A, Van den Steen G, et al. Role of the ductal transcription factors HNF6 and Sox9 in pancreatic acinar-to-ductal metaplasia. Gut. 2012 Dec;61(12):1723-32.

59 Tulachan SS, Doi R, Kawaguchi Y, Tsuji S, Nakajima S, Masui T, et al. All-trans retinoic acid induces differentiation of ducts and endocrine cells by mesenchymal/epithelial interactions in embryonic pancreas. Diabetes. 2003 Jan;52(1):76-84.

60 Arima K, Ohmuraya M, Miyake K, Koiwa M, Uchihara T, Izumi D, et al. Inhibition of 15PGDH causes Kras-driven tumor expansion through prostaglandin E2-ALDH1 signaling in the pancreas. Oncogene. 2019 02;38(8): 1211-24.
61 Colvin EK, Susanto JM, Kench JG, Ong VN, Mawson A, Pinese M, et al. Retinoid signaling in pancreatic cancer, injury and regeneration. PLoS One. 2011;6(12):e29075.

62 Lytle NK, Ferguson LP, Rajbhandari N, Gilroy K, Fox RG, Deshpande A, et al. A multiscale map of the stem cell state in pancreatic adenocarcinoma. Cell. 2019 Apr;177(3):57286.e22.

63 Apte MV, Pirola RC, Wilson JS. Pancreatic stellate cells: a starring role in normal and diseased pancreas. Front Physiol. 2012;3:344.

64 McCarroll JA, Naim S, Sharbeen G, Russia N, Lee J, Kavallaris M, et al. Role of pancreatic stellate cells in chemoresistance in pancreatic cancer. Front Physiol. 2014;5:141.

65 Apte MV, Wilson JS. Dangerous liaisons: pancreatic stellate cells and pancreatic cancer cells. J Gastroenterol Hepatol. 2012 Mar; 27(Suppl 2):69-74.

66 Ota S, Nishimura M, Murakami Y, Birukawa NK, Yoneda A, Nishita $\mathrm{H}$, et al. Involvement of pancreatic stellate cells in regeneration of remnant pancreas after partial pancreatectomy. PLoS One. 2016;11(12):e0165747.

67 Froeling FE, Feig C, Chelala C, Dobson R, Mein CE, Tuveson DA, et al. Retinoic acidinduced pancreatic stellate cell quiescence reduces paracrine Wnt- $\beta$-catenin signaling to slow tumor progression. Gastroenterology. 2011 Oct;141(4):1486-97.e1-14.

68 Brun PJ, Wongsiriroj N, Blaner WS. Retinoids in the pancreas. Hepatobiliary Surg Nutr. 2016 Feb;5(1):1-14.

69 Vonlaufen A, Joshi S, Qu C, Phillips PA, Xu Z, Parker NR, et al. Pancreatic stellate cells: partners in crime with pancreatic cancer cells. Cancer Res. 2008 Apr;68(7):2085-93.

70 Rhim AD, Oberstein PE, Thomas DH, Mirek ET, Palermo CF, Sastra SA, et al. Stromal elements act to restrain, rather than support, pancreatic ductal adenocarcinoma. Cancer Cell. 2014 Jun;25(6):735-47.

71 Wilson JS, Pirola RC, Apte MV. Stars and stripes in pancreatic cancer: role of stellate cells and stroma in cancer progression. Front Physiol. 2014;5:52.

72 Laklai H, Miroshnikova YA, Pickup MW Collisson EA, Kim GE, Barrett AS, et al. Genotype tunes pancreatic ductal adenocarcinoma tissue tension to induce matricellular fibrosis and tumor progression. Nat Med. 2016 May;22(5):497-505.

73 Dunér S, Lopatko Lindman J, Ansari D, Gundewar C, Andersson R. Pancreatic cancer: the role of pancreatic stellate cells in tumor progression. Pancreatology. 2010;10(6): 673-81.

74 Haqq J, Howells LM, Garcea G, Metcalfe MS Steward WP, Dennison AR. Pancreatic stellate cells and pancreas cancer: current perspectives and future strategies. Eur J Cancer. 2014 Oct;50(15):2570-82.

75 Friedman SL. Hepatic stellate cells: protean, multifunctional, and enigmatic cells of the liver. Physiol Rev. 2008 Jan;88(1):125-72.

76 Carmona R, Barrena S, Muñoz-Chápuli R. Retinoids in stellate cells: development, repair, and regeneration. J Dev Biol. 2019 May; $7(2)$. 
77 McCarroll JA, Phillips PA, Santucci N, Pirola RC, Wilson JS, Apte MV. Vitamin A inhibits pancreatic stellate cell activation: implications for treatment of pancreatic fibrosis. Gut. 2006 Jan;55(1):79-89.

78 Carapuca EF, Gemenetzidis E, Feig C, Bapiro TE, Williams MD, Wilson AS, et al. Anti-stromal treatment together with chemotherapy targets multiple signalling pathways in pancreatic adenocarcinoma. J Pathol. 2016 Jul; 239(3):286-96.

79 Klonowski-Stumpe H, Fischer R, Reinehr R, Lüthen R, Häussinger D. Apoptosis in activated rat pancreatic stellate cells. Am J Physiol Gastrointest Liver Physiol. 2002 Sep; 283(3):G819-26.

80 Chronopoulos A, Robinson B, Sarper M, Cortes E, Auernheimer V, Lachowski D, et al. ATRA mechanically reprograms pancreatic stellate cells to suppress matrix remodelling and inhibit cancer cell invasion. Nat Commun. 2016 Sep; 7:12630

81 Goulart MR, Watt J, Siddiqui I, Lawlor RT, Imrali A, Hughes C, et al. Pentraxin 3 is a stromally-derived biomarker for detection of pancreatic ductal adenocarcinoma. NPJ Precis Oncol. 2021 Jun 29;5(1):61.

82 Huang X, Gao Y, Zhi X, Ta N, Jiang H, Zheng J. Association between vitamin A, retinol and carotenoid intake and pancreatic cancer risk: evidence from epidemiologic studies. Sci Rep. 2016 Dec;6:38936.

$83 \mathrm{Xu}$ XC. Tumor-suppressive activity of retinoic acid receptor-beta in cancer. Cancer Lett. 2007 Aug;253(1):14-24.

84 Polvani S, Tarocchi M, Tempesti S, Galli A. Nuclear receptors and pathogenesis of pancreatic cancer. World J Gastroenterol. 2014 Sep;20(34):12062-81.

85 Rhim AD, Stanger BZ. Molecular biology of pancreatic ductal adenocarcinoma progression: aberrant activation of developmenta pathways. Prog Mol Biol Transl Sci. 2010;97: 41-78.

86 Guan J, Zhang H, Wen Z, Gu Y, Cheng Y, Sun $\mathrm{Y}$, et al. Retinoic acid inhibits pancreatic cancer cell migration and EMT through the downregulation of IL-6 in cancer associated fibroblast cells. Cancer Lett. 2014 Apr;345(1): 132-9.
87 Herreros-Villanueva M, Er TK, Bujanda L. Retinoic acid reduces stem cell-like features in pancreatic cancer cells. Pancreas. 2015 Aug; 44(6):918-24.

88 Davis-Yadley AH, Malafa MP. Vitamins in pancreatic cancer: a review of underlying mechanisms and future applications. Adv Nutr. 2015 Nov;6(6):774-802.

89 Recchia F, Sica G, Candeloro G, Bisegna R, Bratta M, Bonfili P, et al. Chemoradioimmunotherapy in locally advanced pancreatic and biliary tree adenocarcinoma: a Multicenter Phase II Study. Pancreas. 2009 Aug;38(6): e163-8.

90 Kuroda H, Tachikawa M, Uchida Y, Inoue K, Ohtsuka H, Ohtsuki S, et al. All-trans retinoic acid enhances gemcitabine cytotoxicity in human pancreatic cancer cell line AsPC-1 by upregulating protein expression of deoxycytidine kinase. Eur J Pharm Sci. 2017 May 30; 103:116-21.

91 Yao J, Zhang L, Zhou J, Liu H, Zhang Q. Efficient simultaneous tumor targeting delivery of all-trans retinoid acid and Paclitaxel based on hyaluronic acid-based multifunctional nanocarrier. Mol Pharm. 2013 Mar 04;10(3): 1080-91.

92 Pettersson F, Colston KW, Dalgleish AG. Retinoic acid enhances the cytotoxic effects of gemcitabine and cisplatin in pancreatic adenocarcinoma cells. Pancreas. 2001 Oct;23(3): 273-9.

93 Wang K, Baldwin GS, Nikfarjam M, He H. Antitumor effects of all-trans retinoic acid and its synergism with gemcitabine are associated with downregulation of p21-activated kinases in pancreatic cancer. Am J Physiol Gastrointest Liver Physiol. 2019 05;316(5): G632-G40.

94 Sun R, Liu Y, Li SY, Shen S, Du XJ, Xu CF, et al. Co-delivery of all-trans-retinoic acid and doxorubicin for cancer therapy with synergistic inhibition of cancer stem cells. Biomaterials. $2015 \mathrm{Jan} ; 37: 405-14$
95 Thomas D, Radhakrishnan P. Tumor-stromal crosstalk in pancreatic cancer and tissue fibrosis. Mol Cancer. 201901 21;18(1):14.

96 Kakwere H, Ingham ES, Tumbale SK, Ferr ara KW. Gemcitabine-retinoid prodrug loaded nanoparticles display in vitro antitumor efficacy towards drug-resilient human PANC-1 pancreatic cancer cells. Mater Sci Eng C Mater Biol Appl. 2020 Dec; 117: 111251

97 Nakagawa T, Shimizu M, Shirakami Y, Tatebe H, Yasuda I, Tsurumi H, et al. Synergistic effects of acyclic retinoid and gemcitabine on growth inhibition in pancreatic cancer cells. Cancer Lett. 2009 Jan;273(2): 250-6.

98 Pili R, Salumbides B, Zhao M, Altiok S, Qian $\mathrm{D}$, Zwiebel J, et al. Phase I Study of the histone deacetylase inhibitor entinostat in combination with 13-cis retinoic acid in patients with solid tumours. Br J Cancer. 2012 Jan;106(1):77-84

99 Cristiano MC, Cosco D, Celia C, Tudose A, Mare R, Paolino D, et al. Anticancer activity of all-trans retinoic acid-loaded liposomes on human thyroid carcinoma cells. Colloids Surf B Biointerfaces. 2017 Feb 01;150:40816.

100 Cheng YH, Chiang EI, Syu JN, Chao CY, Lin HY, Lin CC, et al. Treatment of 13-cis retinoic acid and 1,25-dihydroxyvitamin D3 inhibits TNF-alpha-mediated expression of MMP-9 protein and cell invasion through the suppression of JNK pathway and microRNA 221 in human pancreatic adenocarcinoma cancer cells. PLoS One. 2021;16(3): e0247550.

101 Pishvaian MJ, Blais EM, Brody JR, Lyons E, DeArbeloa P, Hendifar A, et al. Overall survival in patients with pancreatic cancer receiving matched therapies following molecular profiling: a retrospective analysis of the know your tumor registry trial. Lancet Oncol. 2020 Apr;21(4):508-18.

102 Bunaciu RP, Yen A. Retinoid chemoprevention: who can benefit? Curr Pharmacol Rep. 2015 Dec 01;1(6):391-400.

103 Hunsu VO, Facey COB, Fields JZ, Boman BM. Retinoids as chemo-preventive and molecular-targeted anti-cancer therapies. Int J Mol Sci. 2021 Jul 20;22(14) 